\title{
(IN)DEFINICIONES DE LA ESCOLARIZACIÓN EN CONTEXTOS DE DIVERSIDAD ETNOLINGÜÍSTICA. ANÁLISIS DE LA EIB EN ARGENTINA
}

\author{
INDEFINITIONS OF SCHOOLING IN CONTEXTS OF \\ ETHNO-LINGUISTIC DIVERSITY. \\ ANALYSIS OF THE EIB IN ARGENTINA
}

Ana Carolina Hecht*

RESUMO: El objetivo de este artículo es realizar un estado de la cuestión sobre la Educación Intercultural Bilingüe (EIB) en Argentina. Para ello, en un principio, se contextualizan históricamente las políticas educativas para diversidad étnica y lingüística. Luego, se define a la EIB considerando cinco rasgos centrales que la caracterizan actualmente: política compensatoria en el contexto neoliberal, descentralización y regionalización educativa, modalidad del sistema educativo, metas lingüística y debates sobre la capacitación docente. Por último, en las conclusiones, se exponen los desafíos, deudas pendientes y perspectivas a futuro de esta política educativa. Este análisis se efectúa en base a los postulados afirmados en la legislación nacional, bibliografía pertinente y experiencias personales de investigación en el campo de la antropología educativa y lingüística.

Palabras clave: Educación Intercultural Bilingüe, política educativa, diversidad etnolingüística, legislación, Argentina.

\footnotetext{
* Doutora en Ciencias Antropológicas, Docente de la Universidad de Buenos Aires - UBA, Investigadora del Consejo Nacional de Investigaciones Científicas y Técnicas - CONICET; Buenos Aires, Argentina; e-mail: anacarolinahecht@yahoo.com.ar 
ABSTRACT: The purpose of this paper is to state of the question Intercultural Bilingual Education (IBE) in Argentina. For itat first, historically are contextualised educational policies ethnic and linguistic diversity. Then he considering IBE defines five traits that characterize it central moment: compensatory policy in the neoliberal context, decentralization and regionalization of education, educational system mode, linguistic goals and debates on teacher training. Finally, in the conclusions, highlights the challenges, outstanding debt and future prospects of the education policy. This analysis is performed based on the principles affirmed in national legislation relevant literature research and personal experiences in the field of educational anthropology and linguistics.

Keywords: Bilingual Intercultural Education, education policy, ethnolinguistic diversity, legislation, Argentina.

\section{INTRODUCCIÓN}

Desde hace más de treinta años, en Argentina se vienen desarrollando proyectos educativos con el fin de incluir y atender las necesidades de las poblaciones étnicamente diversas que habitan en el territorio nacional. La educación intercultural se presenta como una vía para mejorar el rendimiento escolar de aquellos sectores socioculturales para los cuales la escuela constituye una posibilidad insustituible de participación social, sectores que sin embargo son los que más experimentan el fracaso escolar (Sagastizabal, 2000). En este contexto, las políticas educativas para las poblaciones caracterizadas como socio-étnicamente diferentes se denominan como Educación Intercultural Bilingüe (EIB). Particularmente, la EIB se propone contener a los niños y las niñas indígenas, quienes no sólo se encuentran interpelados por un sistema educativo que no contempla la diversidad sociocultural y lingüística de sus destinatarios, sino que además se encuentran en contextos socioeducativos marcados por situaciones de extrema desigualdad y pobreza estructural.

Ahora bien, a pesar de lo prolongado en el tiempo de las experiencias de EIB en el contexto nacional, son pocos los estudios 
académicos que nos presentan un balance del panorama educativo en Argentina. Con ese fin, el objetivo del presente artículo es realizar un estado de la cuestión acerca de la EIB teniendo en cuenta dos ejes: el primero se propone analizar cómo se la entiende y cómo se la define en su calidad de política educativa, mientras que el segundo plantea los desafíos y perspectivas a futuro de esta política. Es decir, en este escrito se revisan algunas cuestiones complejas referentes a cómo se implementa la EIB como política educativa, tratando de hacer un balance y señalando las grandes tendencias que han marcado y limitado a esta política. Con ese fin, el escrito se divide en tres apartados. En el primero, someramente, se revisan las características que históricamente han tenido las políticas educativas para la alteridad etnolingüística en Argentina. Luego, se sistematiza cómo se define a la EIB en Argentina considerando cinco rasgos centrales: la EIB como política compensatoria en el contexto neoliberal, la descentralización y regionalización educativa, la EIB como una modalidad del sistema educativo, las (in)definiciones acerca de la meta lingüística de la EIB y los debates acerca de la capacitación docente. Por último, en las conclusiones se debate acerca de los desafíos, deudas pendientes y las perspectivas a futuro de esta política educativa.

\section{LAS POLÍTICAS EDUCATIVAS PARA LA ALTERIDAD: UN RECORRIDO HISTÓRICO}

En Argentina, las planificaciones educativas para las minorías étnicas han tenido distintas características según los períodos históricos. En términos generales, se perciben dos tendencias: modelos escolares monolingües donde se marginan y niegan especificidades lingüísticas y culturales bajo pautas hegemónicas y asimilacionistas (políticas homogeneizadoras), y modelos escolares bilingües, aunque insertos en programas compensatorios que en ocasiones son funcionales a las políticas neoliberales, encubriendo las desigualdades socioeducativas (políticas focalizadas). Los primeros son prototípicos de la etapa del establecimiento del Estado Nacional desde fines del siglo XIX hasta el XX, mientras que las segundas se corres- 
ponden con la época contemporánea.

En artículos anteriores (cf. Hecht 2007, 2009, 2010) hemos señalado los vaivenes y las características que estas dos tendencias de los diseños educativos han impregnado en las políticas tendientes a incluir a la diversidad sociocultural. Más allá de la importancia de estas cuestiones, tan sólo nos interesa remarcar aquí que las políticas de EIB en Argentina surgen como políticas educativas focalizadas en el contexto neoliberal y por eso conllevan ese estigma desde su nacimiento. Las políticas neoliberales en educación profundizan el carácter antidemocrático y excluyente de los sistemas educativos a través de la reducción del gasto en educación (privatización) e intensificación de los mecanismos de segmentación de los sistemas educativos (descentralización y regionalización). A su vez, se delinea un contraste entre las consecuencias sociales de las políticas neoliberales y el discurso dominante en el campo cultural en base a la idea de "diversidad", "pluralidad" y "multiculturalidad". Justamente esa discursividad es la que ha posibilitado reformular las políticas educativas neoliberales de descentralización y regionalización en clave étnica para incluir la diversidad sociolingüística en sus diseños, tal como más adelante se detalla.

Sin embargo, la EIB también debe ser comprendida en el marco de las reformas legislativas que a partir de la restitución democrática (desde mediados de la década del 80) reconocen derechos diferenciales para los pueblos indígenas. En relación con estas políticas de carácter étnico se percibe que el discurso oficial atenúa su histórica mirada etnocéntrica (Falaschi, 1998) para reconocer la pluralidad étnica. En el año 1994 se produce un punto de inflexión con la Reforma de la Constitución Nacional, dado que se modifican las obligaciones del Estado para con las comunidades indígenas:

"Son atribuciones del Congreso de la Nación: Reconocer la preexis-
tencia étnica y cultural de los pueblos indígenas argentinos. Garan-
tizar el respeto a su identidad y el derecho a una educación bilingüe
e intercultural; reconocer la personería jurídica de sus comunidades
y la posesión y propiedad comunitarias de las tierras que tradicio- 
nalmente ocupan; regular la entrega de otras aptas para el desarrollo humano; ninguna de ellas será enajenable, transmisible ni susceptible de gravámenes o embargos. Asegurar su participación en la gestión referida a sus recursos naturales y a los demás intereses que los afecten" (Constitución Nacional de la República Argentina, Artículo $\mathrm{N}^{\circ} 75$, Inciso $\mathrm{N}^{\circ} 17$ ).

Este cambio discursivo en la Carta Magna vino precedido y seguido de distintas leyes nacionales y provinciales ${ }^{1}$ para el reconocimiento étnico de las tan negadas poblaciones indígenas que habitan el territorio nacional. En síntesis, este cambio legislativo significó a nivel jurídico-político, el tránsito de una política integracionista hacia una de reconocimiento de la pluralidad y respeto por las identidades étnicas y culturales de Argentina. No obstante, como sostiene Falaschi (1998), la normativa existente funciona más como una declaración de principios "del deber ser" que como una base operativa para intervenciones consecuentes. $\mathrm{O}$ sea, cotidianamente se constata la ausencia de voluntad política para ejecutar la normativa en acciones de reconocimiento, aumentando el hiato entre el discurso y la práctica. Además, citando a Petz (2006 [2002]), no debe subestimarse que la orientación política neoliberal no tiende a una transformación de las relaciones que generan la subalternidad de los pueblos indígenas, sino que contraria y paradójicamente, apunta a profundizar las desigualdades bajo el amparo de un discurso que respeta y/o tolera las diferencias.

En el campo específico de la educación, además de lo afirmado en la Constitución Nacional se cuenta con una amplia legislación que a nivel nacional se promulga en favor del establecimiento de una EIB: Resolución N ${ }^{\circ} 107$ del Consejo Federal de Cultura y Educación (1999), Resolución No 549 del Ministerio de Educación Ciencia y Tecnología de la República Argentina (2004), Ley de Educación

\footnotetext{
${ }^{1}$ A modo de ejemplo, durante la década del '80 surgen muchas leyes que contemplan la cuestión indígena como: Ley Nacional 23.302 (1985) sobre "Política Indígena y Apoyo a las Comunidades Aborígenes" y su Decreto Reglamentario N 155/89 (1989), Formosa: Ley Provincial Integral del Aborigen 426 (1984): Salta: Ley Provincial de Promoción y Desarrollo del Aborigen 6373 (1986); Chaco: Ley Provincial del Aborigen 3258 (1987), entre otras.
} 
Nacional No 26.206 (2006), Documento para la Modalidad de Educación Intercultural Bilingüe en el Sistema Educativo Nacional del Consejo Federal de Educación (2010) y Resolución N ${ }^{0} 105$ del Consejo Federal de Cultura y Educación (2010). ${ }^{2}$ Más allá de las sutiles particularidades entre estas legislaciones, citamos la definición de la Resolución $\mathrm{N}^{\circ} 107$ sobre cómo se entiende a la EIB porque plasma los trazos más generales y más consensuados que caracterizan a esta política a nivel nacional:

“(...) es una educación atenta a la diversidad de culturas y lenguas de las poblaciones a las que responde. Al mismo tiempo considera la relación de estas culturas y lenguas con las sociedades nacionales e internacionales en las que están insertas. (...) Esta educación es intercultural en tanto reconoce el derecho que las poblaciones aborígenes tienen a recuperar, mantener y fortalecer su identidad así como a conocer y relacionarse con otros pueblos y culturas coexistentes en los ámbitos local, regional, nacional e internacional. (...) Esta educación es bilingüe en tanto desarrolla la competencia comunicativa de los educandos, a nivel oral y escrito, en la lengua o lenguas utilizadas en el hogar y en la comunidad, junto con el aprendizaje de otras lenguas de mayor difusión y uso en los ámbitos nacional e internacional". (Resolución 107, Consejo Federal de Cultura y Educación: 5-6).

Más allá del giro novedoso que este modelo educativo parece instaurar en comparación con la tradicional educación homogeneizadora, retomamos el cuestionamiento que efectúan Alonso y Díaz (2004) al supuesto de que la aparición de la educación intercultural implica por sí una modificación del statu quo. Contrariamente, si quisiéramos eso el debate debiera centrarse en el "para qué" y "desde dónde" una escuela y una educación en esos contextos. Sólo desde una

${ }^{2}$ A nivel provincial se cuenta con una copiosa cantidad de leyes que favorecen la EIB en sus jurisdicciones. Incluso, vale explicitar que algunas provincias recientemente han incluido a las lenguas indígenas como lenguas oficiales, tal es el caso del Chaco que en el año 2010 declaró ese estatus al wichí, toba y mocoví además del español. Más aún, actualmente en dicha provincia se está debatiendo trascender la EIB para proponer escuelas públicas de gestión social indígena (EPGSI), donde las comunidades locales sean las protagonistas de sus proyectos escolares. 
mirada de ese tipo se puede comprender que la educación intercultural bilingüe no se trata sólo de un currículo intercultural y la incorporación de una lengua indígena, sino de relaciones entre sujetos políticos y culturales que no están dados de antemano, sino que se están construyendo políticamente en relaciones jerárquicas y de poder.

Como hemos señalado en artículos anteriores (cf. Hecht 2007 y 2009 y Borton et al. 2010) los vaivenes y las características que los modelos homogenizados y focalizados impregnan en los diseños educativos son múltiples y complejas. Pareciera existir cierto falso dilema entre: inclusión asimilacionista y exclusión segregadora (Borton et al, 2010). Como si fueran las únicas opciones que se presentan en una dicotomía entre un esfuerzo de inclusión de la diversidad que termina siendo - tal vez involuntariamente- asimilacionista y un "rescate" de la diversidad que al folklorizarla y estancarla termina generando segregación. En consecuencia, no podemos dejar de pensar en la distancia que separa el propósito que marcó el surgimiento mismo de la EIB y las formas concretas que ha adoptado la educación intercultural institucionalmente. En este sentido, la EIB no garantiza por sí misma la construcción de relaciones más simétricas dentro de la escuela, y la aceptación y aplicación acrítica de la EIB puede derivar paradójicamente en un refuerzo de la desigualdad en nombre del respeto a la diversidad. Sin embargo, recorriendo caminos distintos, y planteando actitudes distintas ante la diversidad cultural, los efectos de ambas iniciativas terminan asemejándose: ninguno de los dos polos termina por desestabilizar el curriculum hegemónico. En el primer caso, se incluye a los alumnos en un currículo común, pero éste es el hegemónico. En el segundo, termina por elaborarse un currículum que si bien atiende a las particularidades e intereses de la comunidad, termina por cerrarse sobre sí mismo. Siguiendo a Connell:

"Los currícula separados y diferentes tienen cierto atractivo, pero dejan intacto el currículum hegemónico en vigor. La justicia social requiere cambiar de punto de partida para reconstruir la corriente principal, de forma que encarne los intereses de las personas menos 
favorecidas" (Connell, 1997, p.65).

De esta manera, ambas iniciativas distan de resultar efectivamente democratizantes en la medida que no cuestionan los efectos homogeneizadores del currículum hegemónico y, aunque embanderadas de buenas intenciones, profundizan la desigualdad que intentan combatir.

A continuación, tomando como base los postulados afirmados en la legislación mencionada en los párrafos precedentes, así como la bibliografía leída y mi propia experiencia de investigación en este campo ${ }^{3}$, se sistematizarán algunas características que consideramos centrales para comprender a la EIB en Argentina.

\section{3 ¿CÓMO SE DEFINE A LA EDUCACIÓN INTERCULTU- RAL BILINGÜE?}

Una vez caracterizada a la EIB como política atenta a la diversidad lingüística y sociocultural, en este apartado se procura definirla a partir de algunos rasgos salientes que le imprimen su sello particular como política educativa. Pero, antes de avanzar, cabe aclarar que si se pretenden sistematizar rasgos comunes entre los distintos proyectos de EIB en el territorio argentino, la primera característica compartida que sobresale es el hecho de que éstos no superan el nivel experiencial. Es decir, las propuestas de EIB suelen presentarse como experiencias - por lo común aisladas-donde la variabilidad es la característica constante y donde los lineamientos generales emitidos en la legislación nacional y provincial sobre EIB no son más que una tenue sombra que acompaña a las acciones. Si bien sabemos que la solución tampoco es pensar en una única política general para atender la diversidad de casos, creemos que este es un bache que no podemos dejar de mencionar, ya que "(...) la EIB no puede ser solo un proyecto de la escuela, sin negar la importancia de que lo sea" (Novaro, 2002: 18). Como corolario, las decisiones respecto de la implementación (o no) de la EIB dependen de la "voluntad" de los

\footnotetext{
${ }^{3}$ Me refiero a investigaciones etnográficas efectuadas desde 2001 hasta el presente en el campo de la antropología lingüística y educativa con comunidades wichís y chorotes de Salta, wichís de Formosa y tobas (qom) de Buenos Aires y Chaco.
} 
actores locales involucrados (directivos, maestros, padres), por ello se encuentran proyectos en donde el abordaje de la interculturalidad en la escuela es visto como un problema, el bilingüismo una deuda pendiente y el plurilingüismo una utopía. Es decir, hay casos en donde los niños son alfabetizados en las lenguas indígenas; otros en donde se proponen metas bilingües o con enfoques de enseñanza del español como segunda lengua; hasta casos en donde los alumnos son alfabetizados en español solamente y cuentan con alguna asignatura que se propone incluir contenidos culturales supuestamente significativos para los niños y niñas indígenas.

En consecuencia, muchas de las propuestas de EIB corren el riesgo de transformarse en propuestas devaluadas que finalmente terminan por aumentar la fragmentación educativa, porque su implementación en proyectos y acciones específicas depende exclusivamente de la voluntad de los gobiernos provinciales, e incluso de la iniciativa de los docentes y los directivos escolares o de los reclamos de los padres y madres indígenas. Por tal razón, no puede hacerse referencia a "una política" de educación intercultural en Argentina, ya que no existe un único lineamiento educativo, sino que hay diversos proyectos en distintos lugares y con características bastante diferenciadas. Pese a esta limitante, en las siguientes páginas procuraremos aislar aquellas marcas más recurrentes a partir de distintas experiencias de EIB. En particular, sólo nos vamos a focalizar en cinco rasgos que tiene la EIB en Argentina: 1) La EIB como política compensatoria en el contexto neoliberal, 2) La descentralización y regionalización de la educación, 3) La EIB como una modalidad del sistema educativo, 4) Las (in)definiciones acerca de la meta lingüística de la EIB, 5) Los debates acerca de la capacitación docente para la EIB. A continuación, ampliaremos muy someramente cada uno de los aspectos enumerados para establecer un balance de la EIB en Argentina.

\subsection{La EIB como política compensatoria en el contexto neoliberal}

La EIB, en oposición a las políticas homogeneizadoras, se ha planteado como una política educativa que pugna por trascender los 
estereotipos que identifican a la diversidad sociocultural con carencias (educativas, lingüísticas, culturales, cognitivas). Es decir, surge con la ilusión de que el lema "somos todos iguales" se reactualice en "somos todos diferentes".

No obstante, no logra revertir esa mirada en su diseño original ya que, cuando en el año 2004 el Ministerio de Educación de la República Argentina crea el Programa Nacional de Educación Intercultural Bilingüe, queda elaborado y bajo la supervisión de la Dirección Nacional de Programas Compensatorios, dependiente de la Subsecretaria de Equidad y Calidad. Así, se atenta contra la idea de que el enfoque intercultural se debe instaurar a nivel general y transversal al sistema escolar para romper con los estereotipos que asimilan la diversidad cultural con una desventaja socioeducativa. En otras palabras, enmarcar la diversidad dentro de las políticas compensatorias parece implicar como supuesto que la diversidad es un problema o carencia a subsanar. En un sentido similar, Sagastizabal (2000) plantea que la diferencia cultural se transforma en deficiencia, en tanto la diversidad se equipara con "carencias" que se intentan paliar a través de políticas educativas compensatorias. Además, a través de ese movimiento, los programas de EIB se presentan como planes de compensación perdiendo de vista que más bien son un campo de derechos luchados y ganados por las comunidades y organizaciones indígenas. O sea, paradójicamente, este tipo de programas reproducen la folklorización y la reducción de la problemática indígena al plano de la asistencia social y al ámbito rural (Hecht y Szulc, 2006), así como el supuesto de que la diversidad es un defecto a compensar. En resumen, tal como analizan Alonso y Díaz (2004), se debe estar alerta frente a la despolitización del discurso de la diversidad ya que no se habla más de desigualdad social sino de diversidad cultural, bajo el supuesto falso de que la desigualdad no se puede eliminar pero las diferencias pueden articularse armónicamente.

Asimismo, es importante acentuar que debemos estar atentos ya que dentro de este movimiento particularista de "rescatar lo étnico" se encubren otra serie de inconvenientes. En tanto "es necesario discriminar entre las voces que sostienen estos proyectos, 
aquéllas que se proponen auténticamente lograr sistemas educativos inclusivos, de aquéllas otras que, predominan desde los organismos nacionales e internacionales y que, tras el discurso de la diversidad, omiten referirse al carácter crecientemente desigual de nuestra sociedad" (Bordegaray y Novaro, 2004: 9). Es decir, debemos tener presente "la funcionalidad que el discurso de la diversificación de la oferta ha tenido con relación a los procesos de creciente fragmentación, atomización y desigualdad educativa. Esto no implica renunciar a la defensa de la diversidad, pero sí estar atentos a los "usos" de la que es objeto, para que el "discurso de la diversidad" no implique el renunciamiento a la idea de justicia e igualdad en el goce de los derechos" (Bordegaray y Novaro, 2004: 9). Estas reflexiones nos invitan a repensar la interculturalidad, ya que este tipo de proyectos particularistas pueden ser funcionales al encubrimiento de la desigualdad socio-educativa, detrás de un rechazo a la generalización de medidas. Más bien, bregamos por una tensión constante entre las políticas particularistas y universalistas, sin que una implique la negación de la otra.

Ahora bien, más allá de estas críticas, se debe hacer una salvedad, ya que en años anteriores el área de EIB pasó a la Dirección Nacional de Gestión Curricular y Formación Docente del Ministerio de Educación Nacional. Es decir, resulta auspiciosa esta reubicación en el organigrama institucional, si bien hasta la actualidad aún no contamos con datos que ratifiquen lo promisorio del cambio. Pero, por lo menos en la estructura institucional se supera la equiparación entre diversidad, diferencia y desventaja.

\subsection{La descentralización y regionalización de la educación}

Frente a un sistema educativo tradicionalmente centralizado como el argentino, la propuesta de la descentralización y regionalización de la educación permite que se visibilicen y valoricen las características locales por medio de acciones tendientes a regionalizar los contenidos curriculares y fortalecer la autonomía de las instituciones educativas. Sin embargo, estos procesos han tenido efectos 
contradictorios en el contexto de las reformas neoliberales. De ese modo, el proceso de descentralización implicó la reducción del gasto público por medio de la transferencia de los servicios educativos del gobierno nacional a las provincias. Por lo tanto, dado que las poblaciones indígenas suelen estar asentadas en las provincias más empobrecidas no logró su cometido democratizador. Tal, como un documento del Ministerio de Educación señala:

"En nuestro país la correlación entre pobreza y analfabetismo en los pueblos indígenas se da en elevados niveles, y pueden advertirse diferencias notables de ese índice entre provincias más ricas y provincias más pobres que involucran tanto población indígena como mestizos, criollos, migrantes o sus descendientes. El Censo de 2001 detectó que las provincias en las que se ubican las ciudades más importantes del país tienen niveles de analfabetismo significativamente menores (Ciudad Autónoma de Buenos Aires, 0,5\%; Santa Fe, 2,5\%, y, Córdoba, 2,1\%) que los de las provincias empobrecidas como Chaco (8\%); Formosa (6\%); Jujuy y Salta (4,7\%). Sin embargo, en estas últimas cuatro se ubica la mayor diversidad de culturas y lenguas originarias vigentes en el país, hecho que se da por la presencia de diversos pueblos indígenas (toba-qom, mocoví, wichí, pilagá, chorote, chané, kolla, diaguita, diaguita-calchaquí, tupi- guaraní, ava guaraní y chulupí) que resisten para permanecer en sus territorios de origen ancestrales." (Documento La Modalidad de Educación Intercultural Bilingüe en el Sistema Educativo Nacional, Consejo Federal de Educación: 6-7)

Así, a través de la propuesta de descentralización y regionalización se legitima la segmentación del sistema educativo entre establecimientos, reproduciendo las desigualdades socioeconómicas que atraviesan a la sociedad argentina. En consecuencia, en vez de propiciar un sistema educativo público equitativo, se cristalizan y acrecientan las desigualdades entre las provincias con y sin recursos materiales, legitimándose la segmentación del sistema educativo según distancias socio-económicas. 
En este sentido, se evidencia cómo la escuela bilingüe intercultural no está unida en una simple ecuación con "reivindicación étnica" y "calidad educativa". Obviamente, nos distanciamos de los discursos neoliberales respecto a qué se entiende por "calidad educativa", sólo hacemos referencia a una posible comparación entre el tipo de escolarización pública que recibe un niño que reside en Buenos Aires y otro que vive en el Chaco a partir de la descentralización y la regionalización educativa.

Para terminar, coincidimos con Acuña y Lapalma (2002) en que pese al reconocimiento y la necesidad de una educación intercultural bilingüe no se notan avances significativos en el diseño y la implementación de esos planes educativos, ya que las condiciones socioeconómicas desfavorables, sumadas a la falta de presupuesto y al desinterés de los sectores gubernamentales hacen que las comunidades aborígenes queden cada vez más aisladas, empobrecidas e imposibilitadas de acceder al derecho a una escolarización que los valorice y respete.

\subsection{La EIB como una modalidad del sistema educativo}

La Ley de Educación Nacional ( $\left.N^{\circ} 26.206\right)$ del año 2006 define distintas modalidades educativas, tales como Educación Técnico Profesional, Educación Artística, Educación Especial, Educación Permanente de Jóvenes y Adultos, Educación Rural, Educación en Contextos de Privación de Libertad, Educación Domiciliaria y Hospitalaria y Educación Intercultural Bilingüe. ${ }^{4}$ Puntualmente, la EIB se presenta como:

"La modalidad del sistema educativo de los niveles de Educación Inicial, Primaria y Secundaria que garantiza el derecho constitucional de los pueblos indígenas, conforme al Art. 75, inc. 17 de la Constitución Nacional, a recibir una educación que contribuya a preservar y fortalecer sus pautas culturales, su lengua, su cosmovi-

\footnotetext{
${ }^{4} \mathrm{La}$ estructura del sistema educativo argentino comprende cuatro niveles (inicial, primario, secundario y superior) en estas ocho modalidades. 
sión e identidad étnica; a desempeñarse activamente en un mundo multicultural y a mejorar su calidad de vida. Asimismo, la Educación Intercultural Bilingüe promueve un diálogo mutuamente enriquecedor de conocimientos y valores entre los pueblos indígenas y poblaciones étnica, lingüística y culturalmente diferentes, y propicia el reconocimiento y el respeto hacia tales diferencias" (Ley de Educación Nacional, Capítulo XI, Artículo 52).

Esta definición de la EIB la acota como una de las modalidades del sistema educativo para los pueblos indígenas en los tres primeros niveles educativos de los cuatro contemplados por el sistema (Inicial, Primaria y Secundaria, Superior). Asimismo, importa señalar que se entiende por modalidades a:

"aquellas opciones organizativas y/o curriculares de la educación común, dentro de uno o más niveles educativos, que procuran dar respuesta a requerimientos específicos de formación y atender particularidades de carácter permanente o temporal, personales y/o contextuales, con el propósito de garantizar la igualdad en el derecho a la educación” (Ley de Educación Nacional, Capítulo I, Artículo 17).

Esta definición nos plantea ciertas dudas respecto de su alcance, ya que sostiene que la EIB es la modalidad del sistema exclusivamente para los pueblos indígenas. La reducción de los destinatarios de la EIB "sólo para indígenas", hace perder de vista la transversalidad que debieran tener las propuestas de EIB. La interculturalidad debiera incluir a toda la sociedad y atravesar a todo el sistema educativo, y no sólo a los sujetos portadores de "marcas étnicas". En ese sentido, es necesario que se repiensen los proyectos áulicos para que los diseños interculturales permeen a todo el sistema, trascendiendo la centralidad que sólo se atribuye a determinados sujetos que parecen ser los legítimos depositarios de una EIB. Es decir, quedan excluidos como destinatarios los niños, niñas y jóvenes no indígenas, así como también las poblaciones migrantes de distintos países que viven en Argentina. Por ende, sólo las denominadas minorías 
indígenas son las destinatarias privilegiadas por sobre cualquier otro agrupamiento, que aunque esté menos "marcado", también debiera ser contemplado. Insistimos en la importancia de criticar una definición tan acotada de los destinatarios, ya que no se supera la visión segmentaria y guettizadora de la educación, para percibir que la interculturalidad atañe a toda la sociedad en su conjunto y no sólo a los indígenas. Focalizar los destinatarios a un tipo particular de sujeto (los "pueblos indígenas") en un contexto como el de Argentina es una decisión muy compleja por varias razones. Por un lado, por el mismo alcance asignado a la definición de lo indígena -en relación con el ámbito rural y comunitario, estableciendo un isomorfismo entre área indígena y zonas rurales, e instaurando al espacio urbano como invisibilizador de la alteridad-; y por otro lado, porque en Argentina no sólo se cuenta con población indígena sino con una numerosa proporción de migrantes. Y como consecuencia, se producen formas negadas y fragmentarias de discriminación aún en el marco de una política que se propone inclusiva. Más aún, según el censo nacional de población (2001) del Instituto Nacional de Estadística y Censos (INDEC) viven en el país: 1) 4,2\% de extranjeros: de los cuales el $27,5 \%$ habla una lengua europea y un $42,2 \%$ viene de países que pueden implicar el uso de una lengua indígena (guaraní, aymara y quechua); 2) 1,6\% de la población nacional se auto-reconoce como perteneciente o descendiente de un pueblo indígena u originario: hay veintinueve pueblos indígenas y se hablan catorce lenguas. Más aún, estos datos aumentan si consideramos que el 2,8\% de los hogares de todo el país reconoce tener por lo menos un integrantes perteneciente a un pueblo indígena (datos de la ECPI, 2004 y 2005).

Por otra parte, un rasgo llamativo de las experiencias de EIB es que se han preocupado centralmente por los niveles inferiores de la escolarización (inicial y los dos primeros años de la escuela primaria), con el fin de revertir situaciones de alto ausentismo y abandono de los alumnos indígenas. A modo de ejemplo, según el Relevamiento Anual del año 2009 efectuado por la Red Federal de Información Educativa, se constatan 424 unidades educativas de educación inicial en modalidad de EIB (412 de gestión estatal y 12 de gestión pri- 
vada) con un total de 8.451 alumnos matriculados; en nivel primario hay 720 unidades educativas de EIB (710 del sector de gestión estatal y 10 de gestión privada) con un total de 39.026 alumnos; mientras que en nivel medio hay 220 unidades educativas (211 estatales y 9 privadas) con un total de 8.049 alumnos matriculados. Notoriamente a través de estos números percibimos cómo el foco está puesto en el nivel primario, dejando a un segundo plano el nivel medio, y negando absolutamente el nivel superior. Este hecho trae como corolario una discontinuidad de las propuestas de EIB a lo largo del ciclo escolar como una constante en casi todas las experiencias educativas nacionales. De ese modo, se atenta contra un proyecto educativo que forme sujetos capaces de valorar su patrimonio lingüístico y cultural a lo largo de toda su trayectoria escolar.

\subsection{Las (in)definiciones acerca de las metas lingüísticas de la EIB}

La EIB propone acciones para incluir a las lenguas indígenas en los procesos de escolarización de las niñas y niños que se reconocen como pertenecientes a los distintos pueblos originarios. No obstante, no hay menciones explícitas sobre cómo incluir a las distintas lenguas en la escolarización. Si seguimos la propuesta de López (1988) entendemos que la política lingüística está en íntima asociación con la planificación educativa ya que a través de ésta se expresan los supuestos sobre cómo parece factible modificar, prescribir y jerarquizar las relaciones asimétricas entre las lenguas que coexisten en un Estado. De modo que este vacío en cuanto a cómo planificar y gestionar la diversidad lingüística no puede considerarse un hecho de menor jerarquía.

Estas imprecisiones en las definiciones resultan sorprendentes ya que Argentina se caracteriza por una enorme diversidad sociolingüística. En la actualidad se hablan un total de catorce lenguas indígenas y la situación de cada una de ellas es muy diferente, se trata de un abanico con una multiplicidad de opciones y matices: lenguas que se hablan habitualmente en la vida cotidiana, lenguas se hablan comúnmente y toman prestados términos de otras lenguas, lenguas 
que conviven tras distintos tipos de bilingüismos o multilingüismos, lenguas que lentamente dejan de hablarse y son reemplazadas por otras lenguas. Sin embargo, más allá de esta pluralidad la EIB, más por omisión que por explicitación, parece diseñada sobre un único ideal: niños de comunidades indígenas rurales hablantes de una lengua indígena. No obstante, justamente, cabe citar que según la Encuesta Complementaria de Pueblos Indígenas (2004 y 2005) el 73\% de los indígenas de Argentina afirma no hablar ni entender ninguna lengua indígena frente a un $20 \%$ que tiene esas competencias y un $7 \%$ que no habla pero entiende alguna lengua indígena.

En relación con lo antedicho, también cabe destacar que de toda la legislación sobre educación intercultural bilingüe de Argentina se encuentra una única mención sobre el desplazamiento lingüístico en la Resolución No 549 (2004) que crea al Programa Nacional de Educación Intercultural Bilingüe dependiente de la Dirección Nacional de Programas Compensatorios (Ministerio de Educación, Ciencia y Tecnología de la República Argentina):

"Esta educación es bilingüe en tanto desarrolla la competencia comunicativa de los educandos, a nivel oral y escrito, en la lengua o lenguas utilizadas en el hogar y en la comunidad, junto con el aprendizaje de otras lenguas de mayor difusión y uso en los ámbitos nacional e internacional. También puede ser considerada como bilingüe cuando en casos de retracción lingüística, existe una voluntad consciente de recuperación de la lengua" (Resolución № 549).

Al remitirse a la retracción lingüística -se promulga como requisito previo a la intervención- la necesidad de "una voluntad consciente de recuperación de la lengua". Sin embargo, esa mirada está desconociendo los procesos hegemónicos de dominación y estigmatización que median entre una "voluntad consciente" y, las valoraciones y connotaciones negativas que subyacen al uso de una lengua minoritaria. Es decir, se omite que estas lenguas han atravesado procesos históricos de sometimiento y represión bajo las políticas educativas homogeneizadoras y que, además, actualmente per- 
dieron espacios sociales de uso en tanto están asociadas al "atraso", la "discriminación" y la "pobreza".

En los lineamientos oficiales, notamos que se carece de una definición clara respecto de si la lengua de instrucción debe ser la lengua indígena, o si deben aplicarse modelos de enseñanza de español como lengua segunda, o si la alfabetización debe ser bilingüe. Además, existen muchas otras realidades desatendidas, como pueden ser niños y niñas que se auto-reconocen como indígenas, pero viven en asentamientos urbanos y no son hablantes de ninguna lengua indígena (cf. Hecht, 2010 y Borton et al., 2010), o niños que hablan más de una lengua indígena (cf. Cervera Novo et al. 2010). Es decir, la planificación lingüística en el marco de la EIB debiera contemplar al menos cuatro niveles cruzados: desde contextos donde el español es la primera lengua de los niños indígenas a casos donde es la segunda, y respecto de las lenguas indígenas desde situaciones en las que es la primera lengua hasta otras donde es la segunda.

En resumen, negar la complejidad sociolingüística conlleva que muchos de los niños destinatarios de la EIB sean expulsados del sistema escolar público con argumentos que le endilgan la culpa a una supuesta "deficiencia cognitiva" cuando en realidad las causas pueden correlacionarse con la invisibilidad de las diversas situaciones sociolingüísticas. Además, el hecho de que las jurisdicciones donde se hablan lenguas aborígenes y variedades dialectales del español en contacto con lenguas indígenas duplican, y hasta triplican, las cifras nacionales de analfabetismo y repitencia (Acuña y Sierra, 2002) puede considerarse como un epifenómeno de esa negación de la diversidad sociolingüística.

\subsection{Los debates acerca de la capacitación docente para la EIB}

La EIB en Argentina funciona con un modelo donde se cuenta con dos maestros a cargo del salón de clases de las escuelas con población indígena, por un lado, está el maestro indígena, y por otro, el maestro no indígena. Al primero -más allá de los diferentes nombres que tiene en cada provincia: ADA (Auxiliar Docentes Aborigen) y 
Profesor Intercultural Bilingüe en Chaco, MEMA (Maestro Especial para la Modalidad Aborigen) en Formosa, Auxiliar Bilingüe en Salta, etc.- correspondería la enseñanza de la lengua indígena y de los denominados "contenidos culturales", mientras que el segundo se encargaría de la enseñanza del español y del resto de las asignaturas (matemática, ciencias sociales, ciencias naturales, literatura, etc.). Frente a estas distintas figuras docentes, una de las cuestiones más polémicas de la EIB radica en las muchas dudas que existen sobre el perfil profesional deseado tanto para el maestro indígena como para el no-indígena.

Respecto de los maestros indígenas, es interesante remarcar que primero surgió la necesidad de incorporar la figura de un docente indígena con el fin de paliar u aminorar la brecha comunicativa entre los maestros monolingües en español y los alumnos monolingües en lenguas indígenas, y luego, como consecuencia de esa incorporación, surgieron los debates acerca del perfil o la capacitación docente (cf. Serrudo, 2010 y Zidarich, 2010). O sea, la escuela bilingüe se ha visto obligada a inventar sus maestros, y en consecuencia se nota una precaria formación inicial de muchos maestros de EIB. Esta particular situación origina tensiones entre el docente indígena y no indígena sobre la legitimidad de esta incorporación (centralmente por la falta de capacitación y certificaciones de los maestros indígenas), así como también entre los maestros indígenas que se incluyeron como primera generación en las escuelas y aquellos que actualmente estarían en condiciones de formar parte de la escuela por la capacitación obtenida, pero no cuentan con cargos vacantes disponibles.

Asimismo, y en relación con lo último señalado, no se encuentra reglamentado el mecanismo de integración de este nuevo agente educativo indígena dentro de la escolarización, sino que cada provincia tiene criterios propios y diferentes para incorporar a estos nuevos maestros. Esto genera grandes arbitrariedades entre los mismos docentes indígenas. En oposición, esta situación de vulnerabilidad y arbitrariedad del docente indígena contrasta con los mecanismos de puntaje y acreditación por medio de los cuales los docentes no indígenas acceden a los cargos por concursos públicos reglamentados. 
También, cabe señalar que aún es insuficiente el número de maestros indígenas designados para atender la EIB de Argentina. Es decir, la extensión de la EIB no logra suplir las necesidades de los alumnos indígenas, tal y como señalan Rosso y Artieda (s/d) para el caso del Chaco (aunque también se puede proyectar al resto del país) no hay escuelas de educación bilingüe intercultural en todas las localidades necesarias, y por lo tanto la mayoría de los niños y niñas aborígenes asiste a escuelas primarias comunes. En consecuencia, existen muchas escuelas con matrícula aborigen que no cuentan con estos maestros o tienen una presencia escasa, como aquellos casos en los que se designa un solo maestro indígena por escuela y este tiene que ir trabajando de manera itinerante en los distintos grados.

El perfil docente y la capacitación deseada tanto para el maestro indígena como para el maestro no indígena se encuentra en un constante debate. Con respecto al maestro no-indígena, encontramos que su formación continua efectuándose en magisterios que mantienen una formación monocultural que no contempla la diversidad sociolingüística de los educandos. Tan sólo existen algunas excepciones donde se cuenta con alguna asignatura de formación intercultural pero no suele alcanzar para construir un perfil docente atento a esa diversidad. En consecuencia, los maestros le temen a las propuestas de EIB porque sienten que amenazan su función como agentes educativos en distintos sentidos: por un lado, creen que sus puestos laborales peligran frente a la figura del docente indígena, y por otro lado, su rol tradicional parece desdibujarse por permanecer en la tensión entre alfabetizar en español o alfabetizar en la lengua indígena y enseñar el español como una segunda lengua. Es decir, padecen la tensión de encontrarse ejerciendo un rol para el que no fueron entrenados en su formación profesional.

Por otra parte, respecto del maestro indígena, hallamos que son excepcionales las experiencias oficiales para su capacitación. En Argentina, tan sólo se cuenta con una institución oficial para la formación de profesores indígenas en educación intercultural, nos referimos al CIFMA (Centro de Investigación y Formación para la 
Modalidad Aborigen) $)^{5}$. Frente a este vacío de propuestas oficiales, cabe destacar que, en general, la formación de los docentes suele realizarse en el marco de proyectos financiados por universidades, fundaciones y ONGs, entre otras. El corolario de esta falta de formación para maestros indígenas es la indefinición de su figura, es decir, se desdibuja su rol dentro de las instituciones escolares, y los mismos suelen quedar relegados a la voluntad de los directivos escolares, y por lo tanto, pasan a cumplir funciones de maestranza, de ayudantía al docente, o funcionar como traductores entre el docente no indígena y los niños. Es decir, se vulnera su rol como agente educativo central de la EIB.

Otra variable en constante debate refiere al tipo de relación que debiera existir entre ambos docentes, ya que son evidentes las asimetrías que existen entre los docentes que forman la pareja pedagógica. Hay experiencias de EIB en donde estos docentes trabajan y planifican sus clases en pareja y colaboración, en otras los maestros indígenas funcionan como "auxiliares del docente", o el docente indígena está a cargo del salón de clases y en otras como simples "traductores" (Hecht, 2006 y Cervera Novo et al., 2010). Es decir, más allá de la función “ideal” asignada a los/as maestros/as indígenas (enseñar la lengua indígena y contenidos culturales significativos) su función es difusa en la práctica cotidiana. Así, las actividades que desarrollan los maestros indígenas dentro de las escuelas varían y se registran casos en los que cumplen funciones de portería y ordenanza, otros en donde trabajan como secretarios o asistentes de los maestros y directivos (sirviendo café y mate, completando formularios, etc.), o casos donde ofician de "puente" o traductores entre el español y la/s lengua/s materna/s de los niños hasta escuelas en donde logran cumplir sus funciones didácticas y pedagógicas dentro del aula.

En síntesis, para que lo "lingüístico" y lo "intercultural" en la educación no se transformen tan sólo en adjetivos vacíos o decorativos para las escuelas de modalidad aborigen, es necesario no perder de vista:

\footnotetext{
${ }^{5}$ Esta institución pionera, si bien sentó precedentes respecto de un buen trabajo en cuanto a la capacitación docente -ya que tienen la Carrera de Profesor Intercultural Bilingüe para la Educación General Básica (1 y 2)-, sólo atiende solo a tres lenguas indígenas (wichí, toba y mocoví), por lo cual no logra cubrir el amplio espectro de las catorce lenguas que se hablan en nuestro país. 
“el papel fundamental de los docentes en la implementación de cualquier innovación educativa es ampliamente reconocido. Sin el apoyo y convencimiento de maestros y maestras, la EIB corre el riesgo de quedarse en el discurso de políticos y académicos, y quizás llegue a algunas acciones interesantes pero no al cambio radical que se desea y necesita fomentar. Dado que su espacio de trabajo principal es aún la escuela, desde ella los docentes pueden coadyuvar al fortalecimiento de los procesos de cambio social que las comunidades solicitan” (Nucinkis, 2007 en Serrudo, 2010).

Por todo ello, debemos focalizar labores y acciones que promuevan, valoricen y respeten a los/as maestros/as manteniendo el desafío para que sus acciones contribuyan a edificar una EIB inclusiva y de calidad.

\section{DESAFÍOS Y PERSPECTIVAS A FUTURO}

Una vez presentado este balance sobre la EIB en Argentina, nos proponemos reflexionar sobre los desafíos y las perspectivas a futuro de esta política educativa. En primer lugar, parece imprescindible que se redefinan los límites en la extensión de esta política considerando distintas dimensiones: desde lo geográfico, los destinatarios y los niveles del sistema educativo. Desde lo geográfico, para incluir a las poblaciones indígenas (y migrantes) que habitan en los contextos urbanos rompiendo estereotipos y esencializaciones que asimilan la alteridad y la ruralidad; desde los destinatarios, para contemplar a toda la sociedad y no sólo a las poblaciones marcadas étnicamente como posibles focos de una educación intercultural; y desde los diferentes niveles del sistema educativo, es importante entender que la EIB no es sólo una cuestión pedagógica de los primeros años de inclusión en la escuela sino de trayectorias escolares.

La EIB se encuentra ceñida si no logra trascender el marco escolar para comprender la diversidad sociocultural de su entorno en un sentido político. Las problemáticas de la EIB no sólo deben ser abordadas desde enfoques pedagógicos sino que: 
"la atención a la diversidad lingüística debería atender dos aspectos esenciales: el pedagógico y el etnopolítico. Se trataría, por una parte, de mejorar el aprendizaje y el aprovechamiento escolar, y, por otra, de contribuir a ampliar la funcionalidad comunicativa de los idiomas amerindios (con la consecuente revalorización cultural que conlleva)” (Díaz-Couder, 1998, p.24)

En otras palabras, la educación debe ser comprendida en sentido amplio, en un marco político, y por esa razón creemos que la EIB no debiera ser un fin en sí mismo, sino un medio para producir un cambio en la sociedad (Acuña 2005). Al respecto, coincidimos con Alonso y Díaz (2004) en que la EIB no se hace sólo antropologizando los contenidos curriculares (cultura, diferencia, alteridad se vuelven vocablos de uso corriente), volviendo constructivistas los modos de transmisión y cambiando las actitudes intolerables por otras del respeto por la otredad. Es decir, no sólo hay que pensar el qué y el cómo se educa, sino el para qué y desde dónde de la EIB en el contexto contemporáneo. En otras palabras, hay que politizar el discurso intercultural, y considerar, como ya enfatizamos, que no es sólo un problema educativo sino que es social y político (Alonso y Díaz, 2004).

A partir de lo señalado previamente, en Argentina la EIB parece funcionar más como una política de reconocimiento con el fin de reparar daños pasados, que como una política con miras al futuro. Es decir, parece ser una acción de reparación histórica más que una nueva proyección para la construcción de un Estado pluriétnico. En consecuencia, el resultado es que no se ha avanzado en el diseño de una educación bilingüe intercultural sino que se ha desgastado el concepto hasta merecer la desconfianza, el descrédito y el rechazo de algunas organizaciones indígenas (Acuña 2005). Y esto último es muy peligroso, porque puede resultar contraproducente con la necesidad de repensar el rol de la educación en la conformación de un nuevo modelo de Estado plural.

De este modo, parece importante partir de una mirada que descolonice la EIB, que reflexione sobre las relaciones de subalterni- 
dad por fuera de la escuela. En otras palabras, la EIB tiene que salir del aula y ser reconocida como un campo de derechos luchados y ganados por colectivos indígenas, ya que si bien en el plano educativo surge el derecho a una EIB atenta a la diversidad cultural y lingüística del país, esta política educativa procede como si la escuela estuviera aislada del contexto histórico y sociocultural, omitiendo la inferiorización y subordinación que afecta al grupo social de pertenencia de los niños, niñas y jóvenes indígenas.

En ese sentido, el enfoque descolonizador es importante porque posibilita quebrar los discursos colonialistas que anulan las diferencias para transformar las relaciones políticas, sociales, económicas y culturales. Es decir, politizar el discurso intercultural para considerar que no es sólo un problema educativo, sino que es sociopolítico. Así, la meta no es simplemente reconocer y tolerar lo diferente dentro de la matriz establecida, sino implosionar sobre las estructuras coloniales implícitas del poder para conceptualizar a la diversidad desde otra perspectiva. Ese parece ser el mayor desafío que tiene la EIB si pretende instaurarse como una política con perspectivas a futuro.

\section{REFERENCIAS:}

ACUÑA, Leonor. Los chicos mismos te enseñan: bilingüismo en la educación intercultural bilingüe. In: MOLINA, Tissera de, A. y ZIGARÁN, J. (Comp.) Lenguas, educación y culturas. Salta: CEPIHA y Departamento de Lenguas Modernas, Universidad Nacional de Salta, 2005, pp. 21-44.

ACUÑA, Leonor y LAPALMA, María Gabriela. Lenguas en la Argentina. Informe de Cultura y Sustentabilidad en Iberoamérica-ICSI. Barcelona: Fundación Interarts, 2002.

ACUÑA, Leonor y SIERRA, María Concepción. Educación intercultural bilingüe en el departamento Ramón Lista (provincia de Formosa): comparación de propuestas y situación actual. In: SALVIO, Menéndez; CORTÉS, Adriana; MENEGOTTO, Andrea y CÓCORA, Amalia (Eds.) Las teorías lingüisticas frente al nuevo siglo. Actas del VIII Congreso de la Sociedad Argentina de 
Lingüística. Mar del Plata: Edición en CD por la Sociedad Argentina de Lingüística, 2002.

ALONSO, Graciela y DÍAZ, Raúl. ¿Es la educación intercultural una modificación del statu quo? In: DÍAZ, Raúl y ALONSO, Graciela (Comp.) Construcción de espacios interculturales. Buenos Aires: Editorial Miño y Dávila, 2004, pp.75-96.

BORDEGARAY, Dora y NOVARO, Gabriela. Diversidad y desigualdad en las políticas de Estado. Reflexiones a propósito del proyecto de Educación Intercultural Bilingüe en el Ministerio de Educación. Cuadernos de Antropología Social. Buenos Aires: UBA, nº19, pp.101-119, 2004.

BORTON, Aristóbulo; ENRIZ, Noelia; GARCÍA PALACIOS, Mariana y HECHT, Ana Carolina. Capítulo 8. Una aproximación a las representaciones escolares sobre el niño indígena como sujeto de aprendizaje. In: HIRSCH, Silvia y SERRUDO, Adriana (Comps.) La Educación Intercultural Bilingüe en Argentina. Identidades, lenguas y protagonistas. Buenos Aires: Novedades Educativas, 2010, pp. 197- 222.

CERVERA NOVO, Juan Pablo, Graciela CORBATO, Ana Carolina HECHT, Soledad LOSADA, Graciela PAIS, Ivanna PETZ y Mariana SCHMIDT. Capítulo 7. EIB en el chaco salteño. Experiencias de capacitación y producción de textos multilingües con auxiliares bilingües. In: HIRSCH, Silvia y SERRUDO, Adriana (Comp.) La Educación Intercultural Bilingüe en Argentina. Identidades, lenguas y protagonistas. Buenos Aires: Novedades Educativas, 2010, pp.177- 196.

CONNELL, Robert. Escuelas y justicia social. Madrid: Ediciones Morata, 1993.

CONSTITUCIÓN NACIONAL DE LA REPUBLICA ARGENTINA,1994.

DÍAZ-COUDER, Eduardo. Diversidad Cultural y Educación en Iberoamérica. Revista Iberoamericana de Educación. Madrid: OEI, no 17, pp.11-30, 1998.

FALASCHI, Carlos. El discurso de la educación bilingüe e intercultural en Argentina. Ponencia presentada en el III Congreso Chileno de Antropología. Noviembre, Universidad Católica de Temuco, 1998.

HECHT, Ana Carolina. De la familia wichí a la escuela intercultural bilingüe: procesos de apropiación, resistencia y negociación (Formosa, Argentina). Cuadernos Interculturales. Viña del Mar: Universidad de Valparaiso, Vol.4, nº, pp.693-113, 2006. 
Educación intercultural bilingüe: de las políticas homogeneizadoras a las políticas focalizadas en la educación indígena argentina. Revista Interamericana de Educación de Adultos. México: OEA, Vol.29, nº 1 , pp.65-85, 2007.

- Desplazamiento de lenguas y educación intercultural bilingüe. Un contrapunto entre políticas educativas y prácticas e ideologías lingüísticas de familias indígenas urbanas. In: MELGAREJO, Patricia (Comp.) Educación Intercultural en América latina. Memorias, horizontes históricos y disyuntivas políticas. México: Universidad Pedagógica Nacional, Consejo Nacional de Ciencia y Tecnología y Plaza y Valdés Editores, 2009, pp. 175-199.

"Todavía no se hallaron hablar en idioma" Procesos de socialización lingüística de los niños en el barrio toba de Derqui, Argentina. LINCOM Studies in Sociolinguistics 09, München, Lincom Europa, academic publications, 2010.

HECHT, Ana Carolina y SZULC, Andrea. Los niños indígenas como destinatarios de proyectos educativos específicos en Argentina. Qinasay. Revista de Educación Intercultural Bilingüe. Cochabamba: GTZ, Vol.4, n4, pp.45-66, 2006.

LEY DE EDUCACIÓN NACIONAL Nº 26.206, 2006.

LÓPEZ, Luis Enrique. Lengua. Santiago de Chile: UNESCO-OREALC, 1988.

NOVARO, Gabriela. Pueblos aborígenes y escuela. Avances y obstáculos en el desarrollo de un enfoque intercultural. In: AAVV. Sistematización de Experiencias en Educación Intercultural y Bilingüe en Argentina. Buenos Aires: Ministerio de Educación, Ciencia y Tecnología, 2002, pp. 481-506.

PETZ, Ivanna Lys. Políticas de Educación Bilingüe en una Formación Social de Fronteras (Chaco salteño y oeste formoseño). Buenos Aires: Edición en CD, CD 1 Colección de Tesis de Licenciatura del Departamento de Cs. Antropológicas de la Facultad de Filosofía y Letras, Universidad de Buenos Aires, Argentina, 2006 [2002].

RESOLUCIÓN Nº107 DEL CONSEJO FEDERAL DE CULTURA Y EDUCACIÓN, 1999.

RESOLUCIÓN N¹05 DEL CONSEJO FEDERAL DE CULTURA Y EDUCACIÓN, 2010. TECNOLOGÍA DE LA REPÚBLICA ARGENTINA, 2004. 
ROSSO, Laura y ARTIEDA, Teresa. Historia de la Educación Aborigen en la Provincia del Chaco (1951-1994). Manuscrito inédito de la Universidad Nacional del Nordeste, s/d.

SAGASTIZABAL, María de los Ángeles. Diversidad Cultural y fracaso escolar. Educación intercultural: de la teoría a la práctica. Rosario: IRICE, 2000.

SERRUDO, Adriana. Indígenas en la escuela: representaciones y tensiones acerca de los docentes indígenas bilingües en Argentina. In: HIRSCH, Silvia y SERRUDO, Adriana (Comps.) La Educación Intercultural Bilingüe en Argentina: Análisis antropológicos de experiencias en comunidades indigenas. Buenos Aires: Novedades Educativas, 2010, pp. 255-272.

ZIDARICH, Mónica. Pareja vulnerable, si las hay: docente originario y docente no originario. In: HIRSCH, Silvia y SERRUDO, Adriana (Comps.) La Educación Intercultural Bilingüe en Argentina: Análisis antropológicos de experiencias en comunidades indígenas. Buenos Aires: Novedades Educativas, 2010, pp. 223-254.

Recebido: 15/08/2013

Aprovado:10/09/2013 